\title{
Converging Evidence for a Fronto-Basal-Ganglia Network for Inhibitory Control of Action and Cognition
}

\author{
Adam R. Aron, ${ }^{1}$ Sarah Durston, ${ }^{6}$ Dawn M. Eagle, ${ }^{3}$ Gordon D. Logan, ${ }^{2}$ Cathy M. Stinear, ${ }^{5}$ and Veit Stuphorn ${ }^{4}$ \\ ${ }^{1}$ Department of Psychology, University of California, San Diego, La Jolla, California 92093, ${ }^{2}$ Department of Psychology, Vanderbilt University, Nashville, \\ Tennessee 37203, ${ }^{3}$ Department of Experimental Psychology, University of Cambridge, Downing Site, Cambridge CB2 3EB, United Kingdom, ${ }^{4}$ The Zanvyl \\ Krieger Mind/Brain Institute, Johns Hopkins University, Baltimore, Maryland 21218, ${ }^{5}$ Movement Neuroscience Laboratory, Department of Sport and \\ Exercise Science, University of Auckland, Auckland 1142, New Zealand, and ${ }^{6}$ Department of Child and Adolescent Psychiatry, Rudolf Magnus Institute for \\ Neuroscience, University Medical Center Utrecht, The Netherlands
}

Key words: Stop signal; cognitive control; response inhibition; brain stimulation; attention deficit hyperactivity disorder; imaging

Imagine you are at an intersection, waiting for the traffic lights. They turn green, and you are about to press the gas pedal, when suddenly a cyclist swerves into your lane. Before your foot has actually moved, you have to rapidly prevent it from moving as planned. This example highlights the everyday function of stopping an action, a form of response inhibition (or behavioral control) that is the main subject of this mini-review. Stopping is a type of control that can be easily, and precisely, studied experimentally. Recent work has begun to reveal its underlying neural basis. This is important because the psychological and neural components of stopping may be shared by other forms of behavioral control, including forms of control that do not necessarily engage the motor system, such as the control of impulses, thoughts, and emotions. Thus, stopping research may lead to insights into self-control as a whole. Furthermore, some forms of neuropsychiatric problems may arise from alterations to the circuitry underlying stopping.

There now exists a wide body of literature on stopping in different species, using a range of neuroscience techniques. Together, these studies show a remarkable convergence of findings regarding the neural circuitry underlying stopping. Our minisymposium presentations at the 2007 meeting of the Society for Neuroscience demonstrate such integration while highlighting our most recent results. Dr. Logan presents a computational model of response control, in terms of a race between Go and Stop processes. Dr. Aron discusses lesion and imaging data, suggesting that stopping is achieved via a fronto-basal-ganglia network, which could intercept the Go process and thus decrease thalamocortical output. Dr. Stinear describes transcranial magnetic stimulation (TMS) studies that demonstrate increased neural inhibition in the motor cortex during movement prevention. Dr. Stuphorn presents neurophysiological data showing that cells in dorsomedial frontal cortex carry executive control signals for

Received Aug. 10, 2007; revised Sept. 11, 2007; accepted Sept. 16, 2007.

D.E.M. was supported by the Wellcome Trust. G.D.L. was supported by the Air Force Office of Scientific Research Grant FA9550-07-1-0192. V.S. was supported by Deutsche Forschungsgemeinschaft Research Fellowship STU 272/ 1-1. C.M.S. thanks Winston Byblow and James Coxon for their valuable contributions to the research described here. Correspondence should be addressed to Adam R. Aron, Department of Psychology, University of California, San Diego, 9500 Gilman Drive, La Jolla, CA 92093. E-mail: adamaron@ucsd.edu.

DOl:10.1523/JNEUROSCI.3644-07.2007

Copyright $\odot 2007$ Society for Neuroscience $\quad$ 0270-6474/07/2711860-05\$15.00/0 both oculomotor and reaching movements. Dr. Eagle presents a rodent model in which frontal and basal ganglia lesions impair stopping and shows how stimulant drugs improve stopping. Dr. Durston shows how stopping may serve as an endophenotype for neuropsychiatric disorders such as Attention Deficit Hyperactivity Disorder (ADHD).

\section{The Stop signal paradigm}

This cognitive psychology paradigm has been particularly fruitful for the study of behavioral control. On each trial, the subject is presented with one of two possible visual Go signals: e.g., press the left button for a leftward-pointing arrow or the right button for a rightward-pointing arrow. On a minority of trials (e.g., $25 \%$ ), a Stop signal (visual or auditory) is presented after the Go signal. The subject is instructed to respond as fast as possible on Go trials and to do their best to inhibit the response when the Stop signal occurs. If the delay between Go and Stop signals is short, the subject is more likely to successfully prevent the planned movement. By varying the delay systematically, one can compute the main dependent variable: the Stop signal reaction time (SSRT). This is the estimate of the speed of the stopping process in the mind/brain. The SSRT can be estimated using a mathematical model that makes some key assumptions, mainly that the Go and Stop processes are independent (Logan and Cowan, 1984). However, research addressing the neural mechanisms underlying Stop signal performance suggests that behavioral inhibition depends on neural inhibition, which does involve interacting (i.e., nonindependent) networks supporting Stop and Go processes (Hanes et al., 1998). Recent computational modeling has addressed this apparent paradox by examining the fit for both behavioral and neurophysiological data to two different models: one in which the Go and Stop processes are fully independent and one in which they interact (Fig. 1a). The interactive model best fits the data but only if the Stop and Go processes are independent for most of their durations and interact strongly for a brief period in their final stages (Boucher et al., 2007). Thus, the independent race model still provides a good approximation of the underlying mechanisms and estimates of SSRT remain valid. The question thus arises: At which point in the brain do the Go and Stop processes interact? 
a
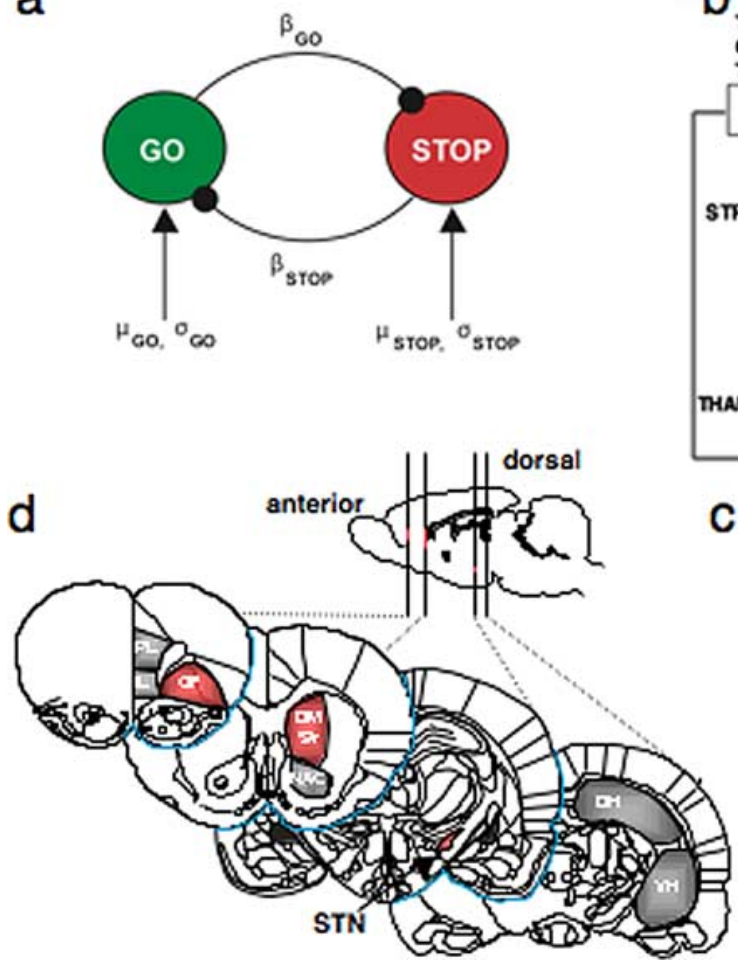

Figure 1. A, The interactive race model between $G 0$ and Stop processes (Boucher et al., 2007). The parameters were estimated by fitting the model to thousands of behavioral trials from a monkey neurophysiology study. $\boldsymbol{B}$, Schematic of fronto-basal-ganglia circuitry for Going and Stopping. The Go process is generated by premotor cortex, which excites striatum and inhibits globus pallidus, removing inhibition from thalamus and exciting motor cortex (see text for details). The stopping process could be generated by inferior frontal cortex leading to activation of the subthalamic nucleus, increasing broad excitation of pallidum and inhibiting thalamocortical output, reducing activation in motor cortex. C, Diffusion-weighted imaging reveals putative white matter tracts in the right hemisphere between the dorsomedial preSMA, the ventrolateral PFC or IFC, and the putative region of the STN. Reproduced with permission from Aron et al. (2007). D, Regions of the rat brain implicated in behavioral stopping. Stopping is significantly impaired following excitotoxic lesions within the regions highlighted in red, whereas lesions within the gray-colored regions have no effect on stopping. OF, Orbitofrontal cortex; IL, infralimbic cortex; PL, prelimbic cortex; DM Str, dorsomedial striatum; NAC, nucleus accumbens (core); DH, dorsal hippocampus; VH, ventral hippocampus; GPi, globus pallidus pars interna.

\section{Lesion and imaging studies in humans}

Sensory information about the Stop signal is quickly relayed to the prefrontal cortex, where the stopping command must be generated. Multiple lines of evidence suggest that the right inferior frontal cortex (IFC) is a critical region for Stop signal response inhibition (Aron et al., 2003; Chambers et al., 2006). The part of the IFC that is most critical probably corresponds to the pars opercularis (Brodmann area 44) in humans. The right IFC could send a Stop command to intercept the Go process via the basal ganglia (Fig. 1b). To appreciate how, first consider the Go process. This is likely generated by premotor areas that project via the direct pathway of the basal ganglia (through striatum, pallidum, and thalamus), eventually exciting primary motor cortex and generating corticospinal volleys to the relevant effector (Aron and Poldrack, 2006). An important point of interaction for Stop and Go processes could be the globus pallidus (Fig. 1b). The Stop process, which often takes $150 \mathrm{~ms}$ or less, could activate the globus pallidus via a projection from the subthalamic nucleus (STN). Highresolution fMRI has shown activation of a midbrain region, consistent with the STN, when subjects successfully stop their responses (Aron and Poldrack, 2006), and diffusion tractography shows that this STN region is directly connected to the right IFC via a white matter tract (Aron et al., 2007) (Fig. 1c).
Thus, once the Stop command is generated in frontal cortex, it could be rapidly conveyed to the basal ganglia via the socalled "hyperdirect pathway" to intercept the Go process in the final stages of the race. Two recent studies identified a third critical node for the stopping process in the dorsomedial frontal cortex, including the presupplementary motor area (preSMA) (Floden and Stuss, 2006; Nachev et al., 2007). Interestingly, the preSMA was also found to be directly connected with both the right IFC and the right STN region via white matter tracts (Aron et al., 2007) (Fig. 1c).

\section{Transcranial magnetic stimulation of} primary motor cortex

The above findings show that preventing a planned movement involves a network of structures within the brain. Their output influences neurons within the primary motor cortex (M1), where descending commands for voluntary movement are generated. The excitability of corticospinal neurons and GABAergic inhibitory neurons within human M1 can be noninvasively studied using TMS. During the Stop signal paradigm, corticospinal excitability increases leading up to movement initiation. However, if there is a Stop signal, the excitability decreases abruptly at a particular time point, and intracortical inhibition increases significantly on successfully stopped trials (Coxon et al., 2006). Rapid increases in intracortical inhibition are also the mechanism underlying selective muscle activation (Stinear and Byblow, 2003), and this is impaired in basal ganglia disorders such as focal hand dystonia (Stinear and Byblow, 2004). Recruitment of inhibition within M1 is most likely the result of activity in the pathways discussed above, which originate in prefrontal cortex and act via the basal ganglia to "brake" the output from M1 (Fig. 1b).

\section{Neurophysiological mechanisms of stopping}

Neural recording studies in monkey ventrolateral PFC have shown increased cellular firing rates during NoGo trials for manual and oculomotor paradigms (Sakagami et al., 2001). Many studies in the monkey have used an oculomotor version of the Stop signal paradigm to investigate neural activity on Go and Stop trials and to reveal signals for movement production, reward, monitoring, and control (for review, see Schall et al., 2002). Above we saw that the dorsomedial frontal cortex is also critical for stopping. Of particular relevance, a recent study showed that microstimulation of neurons in the dorsomedial frontal supplementary eye field improved stopping performance by delaying saccade initiation (Stuphorn and Schall, 2006). Another study recorded from neurons in the adjacent preSMA of monkeys while they performed a switching task designed to examine control over automatic responses (Isoda and Hikosaka, 2007b). When monkeys switched from a well practiced (automatic) task to a less practiced one, preSMA neurons increased activity with sufficient 
speed to influence behavior, as did STN neurons in another study with the same paradigm (Isoda and Hikosaka, 2007a). Furthermore, experimentally induced microstimulation of preSMA neurons led to a greater proportion of switch trials being successful. Combined with the findings in humans that preSMA lesions affect stopping (Floden and Stuss, 2006; Nachev et al., 2007) and that the preSMA is directly connected with the IFC and the STN region (Aron et al., 2007), these findings strongly implicate the dorsomedial frontal cortex in control over motor responses. Future research will need to precisely determine how the nodes in this network interact.

\section{Neural and neurochemical basis of stopping in the rat}

Rodent models of response inhibition offer unique opportunities to investigate the neural and neurochemical substrates of behavioral stopping. Studies of regional excitotoxic lesions support the existence of discrete circuitry between the orbitofrontal cortex and the dorsomedial striatum circuitry that mediates the stopping response, whereas anatomically adjacent regions such as infralimbic cortex, prelimbic cortex, and nucleus accumbens core have no involvement in the stopping process (Eagle and Robbins, 2003a,b; Eagle et al., 2007b) (Fig. 1d). Orbitofrontal cortex in the rodent could be a homologous functional region to lateral prefrontal cortex in the primate (Birrell and Brown, 2000). Lesions to the subthalamic nucleus also impair stopping (Eagle et al., 2007b). These studies reinforce the evidence from human studies that control of stopping is mediated via discrete corticobasal ganglia circuitry.

Pharmacological studies in the rodent highlight distinct roles for noradrenaline and dopamine in distinct processes within the Stop signal task (Eagle et al., 2007a; Robinson et al., 2007). Noradrenaline may be primarily associated with stopping, whereas dopamine may be primarily associated with the Go process. Although serotonin is critical for many forms of behavioral inhibition, it is not involved in the stopping process in rodents, consistent with human studies (Clark et al., 2005; Chamberlain et al., 2006). Interestingly, pharmacological studies indicate that the rats with the longest SSRTs (an ADHD-like phenotype) show the greatest improvements in SSRT following drug administration (D-amphetamine, methylphenidate, modafinil, and atomoxetine) (Feola et al., 2000; Eagle et al., 2007a).

\section{Stopping as an endophenotype for ADHD}

ADHD is a prevalent neuropsychiatric disorder with childhood onset that is partly characterized by executive function problems. Performance of Stop signal and Go-NoGo tasks is often impaired for affected individuals (Nigg, 2001; Lijffijt et al., 2005). Persons with a diagnosis of ADHD show altered brain size in right IFC (Sowell et al., 2003; Durston et al., 2004). They also have decreased functional activation in right IFC for NoGo response inhibition (Casey et al., 1997; Rubia et al., 2003, 2005) and an altered right frontal electroencephalographic signature for the Stop signal task (Pliszka et al., 2000).

Recent work has investigated the familial and genetic basis of ADHD. Impaired stopping performance appears to aggregate in the family members of individuals with ADHD and may serve as an indicator of genetic vulnerability to the disorder (Crosbie and Schachar, 2001; Schachar et al., 2005). Consistent with this, right IFC gray matter and functional activation is reduced in unaffected siblings of children and adolescents with a diagnosis of ADHD (Durston et al., 2004, 2006). Together, these findings suggest that brain structure and function associated with cognitive control may be sensitive to familial and genetic influences, even in the absence of differences at a behavioral level. Other work is investigating putative ADHD genes, such as the dopamine transporter $(D A T 1)$ and dopamine $\mathrm{D}_{4}$ receptor $(D R D 4)$ genes. The $D A T 1$ gene, predominantly expressed in the basal ganglia, influences caudate volume, whereas the DRD4 gene, predominantly expressed in the prefrontal cortex, influences prefrontal gray matter volume (Durston et al., 2005). In healthy control subjects, variations in DRD4 lead to significant differences in SSRT estimates for the Stop signal task (Congdon et al., 2007).

\section{Conclusion}

Research with the cognitively well operationalized Stop signal task strongly suggests that manual responses that are already initiated might be rapidly countermanded by means of frontobasal-ganglia circuitry. The fact that rodent and nonhuman primate models exist for the same task is highly useful for better understanding the connectivity, development, genetic basis, and pharmacology of this control circuit.

It is likely that the simple Stop signal task taps into a control circuit that has wider ecological validity. Variation (or damage) to key nodes in this circuitry (or to their connections) could produce important individual differences, for example, in aspects of personality (Logan et al., 1997), in the response to therapy for eating disorders (Nederkoorn et al., 2006), and in liability toward and recovery from addiction (Garavan and Hester, 2007). Developmental, traumatic, or experimentally induced alterations to key nodes in the control circuit lead to psychiatric symptoms such as inattention (Aron and Poldrack, 2005), impulsivity (Knoch et al., 2006), perseveration (Clark et al., 2007), obsessional thinking (Greenberg et al., 1997), and mania (Mallet et al., 2007) and could also have relevance for movement disorders (Stinear and Byblow, 2004) and stuttering (Brown et al., 2005).

Although stopping a response that is already initiated is a different form of control from such typical measures as Go/NoGo, switching, and interference resolution, much evidence suggests that all of these tasks recruit partly overlapping circuits, especially with respect to the preSMA and the IFC (Konishi et al., 1999; Swainson et al., 2003; Aron et al., 2004; Buchsbaum et al., 2005; Isoda and Hikosaka, 2007b; Nee et al., 2007). Importantly, the network described above may be effector independent, because preSMA, IFC, and the STN are also recruited by NoGo or stopping studies that have examined the control of eye movements (Stuphorn and Schall, 2006; Chikazoe et al., 2007; Hodgson et al., 2007; Isoda and Hikosaka, 2007a,b) and speech (Xue et al., 2006).

There have been reports that the stopping process (and/or regions consistent with the stopping network) may be recruited in the service of controlling thoughts, memory, and emotion (Logan, 1983; Dolcos and McCarthy, 2006; Hourihan and Taylor, 2006; Depue et al., 2007). Thus an important direction for future research is to more precisely examine the possible generality of this network, for the control of information processing over and above the purely motoric.

\section{References}

Aron AR, Poldrack RA (2005) The cognitive neuroscience of response inhibition: relevance for genetic research in attention-deficit/hyperactivity disorder. Biol Psychiatry 57:1285-1292.

Aron AR, Poldrack RA (2006) Cortical and subcortical contributions to Stop signal response inhibition: role of the subthalamic nucleus. J Neurosci 26:2424-2433.

Aron AR, Fletcher PC, Bullmore ET, Sahakian BJ, Robbins TW (2003) Stopsignal inhibition disrupted by damage to right inferior frontal gyrus in humans. Nat Neurosci 6:115-116. 
Aron AR, Monsell S, Sahakian BJ, Robbins TW (2004) A componential analysis of task-switching deficits associated with lesions of left and right frontal cortex. Brain 127:1561-1573.

Aron AR, Behrens TE, Smith S, Frank MJ, Poldrack RA (2007) Triangulating a cognitive control network using diffusion-weighted magnetic resonance imaging (MRI) and functional MRI. J Neurosci 27:3743-3752.

Birrell JM, Brown VJ (2000) Medial frontal cortex mediates perceptual attentional set shifting in the rat. J Neurosci 20:4320-4324.

Boucher L, Palmeri TJ, Logan GD, Schall JD (2007) Inhibitory control in mind and brain: an interactive race model of countermanding saccades. Psychol Rev 114:376-397.

Brown S, Ingham RJ, Ingham JC, Laird AR, Fox PT (2005) Stuttered and fluent speech production: an ALE meta-analysis of functional neuroimaging studies. Hum Brain Mapp 25:105-117.

Buchsbaum BR, Greer S, Chang WL, Berman KF (2005) Meta-analysis of neuroimaging studies of the Wisconsin Card-Sorting task and component processes. Hum Brain Mapp 25:35-45.

Casey BJ, Castellanos FX, Giedd JN, Marsh WL, Hamburger SD, Schubert AB, Vauss YC, Vaituzis AC, Dickstein DP, Sarfatti SE, Rapoport JL (1997) Implication of right frontostriatal circuitry in response inhibition and attention-deficit/hyperactivity disorder. J Am Acad Child Adolesc Psychiatry $36: 374-383$.

Chamberlain SR, Muller U, Blackwell AD, Clark L, Robbins TW, Sahakian BJ (2006) Neurochemical modulation of response inhibition and probabilistic learning in humans. Science 311:861-863.

Chambers CD, Bellgrove MA, Stokes MG, Henderson TR, Garavan H, Robertson IH, Morris AP, Mattingley JB (2006) Executive "brake failure" following deactivation of human frontal lobe. J Cogn Neurosci 18:444-455.

Chikazoe J, Konishi S, Asari T, Jimura J, Miyashita Y (2007) Activation of right inferior frontal gyrus during response inhibition across response modalities. J Cogn Neurosci 19:59-68.

Clark L, Roiser JP, Cools R, Rubinsztein DC, Sahakian BJ, Robbins TW (2005) Stop signal response inhibition is not modulated by tryptophan depletion or the serotonin transporter polymorphism in healthy volunteers: implications for the 5-HT theory of impulsivity. Psychopharmacology (Berl) 182:570-578.

Clark L, Blackwell AD, Aron AR, Turner DC, Dowson J, Robbins TW, Sahakian BJ (2007) Association between response inhibition and working memory in adult ADHD: a link to right frontal cortex pathology? Biol Psychiatry 61:1395-1401.

Congdon E, Lesch KP, Canli T (2007) Analysis of DRD4 and DAT polymorphisms and behavioral inhibition in healthy adults: implications for impulsivity. Am J Med Genet B Neuropsychiatr Genet, in press.

Coxon JP, Stinear CM, Byblow WD (2006) Intracortical inhibition during volitional inhibition of prepared action. J Neurophysiol 95:3371-3383.

Crosbie J, Schachar R (2001) Deficient inhibition as a marker for familial ADHD. Am J Psychiatry 158:1884-1890.

Depue BE, Curran T, Banich MT (2007) Prefrontal regions orchestrate suppression of emotional memories via a two-phase process. Science 317:215-219.

Dolcos F, McCarthy G (2006) Brain systems mediating cognitive interference by emotional distraction. J Neurosci 26:2072-2079.

Durston S, Hulshoff Pol HE, Schnack HG, Buitelaar JK, Steenhuis MP, Minderaa RB, Kahn RS, van Engeland H (2004) Magnetic resonance imaging of boys with attention-deficit/hyperactivity disorder and their unaffected siblings. J Am Acad Child Adolesc Psychiatry 43:332-340.

Durston S, Fossella JA, Casey BJ, Hulshoff Pol HE, Galvan A, Schnack HG, Steenhuis MP, Minderaa RB, Buitelaar JK, Kahn RS, van Engeland H (2005) Differential effects of DRD4 and DAT1 genotype on frontostriatal gray matter volumes in a sample of subjects with attention deficit hyperactivity disorder, their unaffected siblings, and controls. Mol Psychiatry 10:678-685.

Durston S, Mulder M, Casey BJ, Ziermans T, van Engeland H (2006) Activation in ventral prefrontal cortex is sensitive to genetic vulnerability for attention-deficit hyperactivity disorder. Biol Psychiatry 60:1062-1070.

Eagle DM, Robbins TW (2003a) Inhibitory control in rats performing a stop-signal reaction-time task: effects of lesions of the medial striatum and d-amphetamine. Behav Neurosci 117:1302-1317.

Eagle DM, Robbins TW (2003b) Lesions of the medial prefrontal cortex or nucleus accumbens core do not impair inhibitory control in rats performing a stop-signal reaction time task. Behav Brain Res 146:131-144.
Eagle DM, Tufft MR, Goodchild HL, Robbins TW (2007a) Differential effects of modafinil and methylphenidate on stop-signal reaction time task performance in the rat, and interactions with the dopamine receptor antagonist cis-flupenthixol. Psychopharmacology (Berl) 192:193-206.

Eagle DM, Baunez C, Hutcheson DM, Lehmann O, Shah AP, Robbins TW (2007b) Stop-signal reaction-time task performance: role of prefrontal cortex and subthalamic nucleus. Cereb Cortex, in press.

Feola TW, de Wit H, Richards JB (2000) Effects of D-amphetamine and alcohol on a measure of behavioral inhibition in rats. Behav Neurosci 114:838-848.

Floden D, Stuss DT (2006) Inhibitory control is slowed in patients with right superior medial frontal damage. J Cogn Neurosci 18:1843-1849.

Garavan H, Hester R (2007) The role of cognitive control in cocaine dependence. Neuropsychol Rev 17:337-345.

Greenberg BD, George MS, Martin JD, Benjamin J, Schlaepfer TE, Altemus M, Wassermann EM, Post RM, Murphy DL (1997) Effect of prefrontal repetitive transcranial magnetic stimulation in obsessive-compulsive disorder: a preliminary study. Am J Psychiatry 154:867-869.

Hanes DP, Patterson WF, Schall JD (1998) Role of frontal eye fields in countermanding saccades: visual, movement, and fixation activity. J Neurophysiol 79:817-834.

Hodgson T, Chamberlain M, Parris B, James M, Gutowski N, Husain M, Kennard C (2007) The role of the ventrolateral frontal cortex in inhibitory oculomotor control. Brain 130:1525-1537.

Hourihan KL, Taylor TL (2006) Cease remembering: control processes in directed forgetting. J Exp Psychol Hum Percept Perform 32:1354-1365.

Isoda M, Hikosaka O (2007a) Role for the subthalamic nucleus in switching from automatic to controlled behavior. Soc Neurosci Abstr 33:839.15.

Isoda M, Hikosaka O (2007b) Switching from automatic to controlled action by monkey medial frontal cortex. Nat Neurosci 10:240-248.

Knoch D, Gianotti LR, Pascual-Leone A, Treyer V, Regard M, Hohmann M, Brugger P (2006) Disruption of right prefrontal cortex by lowfrequency repetitive transcranial magnetic stimulation induces risktaking behavior. J Neurosci 26:6469-6472.

Konishi S, Nakajima K, Uchida I, Kikyo H, Kameyama M, Miyashita Y (1999) Common inhibitory mechanism in human inferior prefrontal cortex revealed by event-related fMRI. Brain 122:981-991.

Lijffijt M, Kenemans JL, Verbaten MN, van Engeland H (2005) A metaanalytic review of stopping performance in attention-deficit/hyperactivity disorder: deficient inhibitory motor control? J Abnorm Psychol 114:216-222.

Logan G, Schachar R, Tannock R (1997) Impulsivity and inhibitory control. Psychol Sci 8:60-64.

Logan GD (1983) On the ability to inhibit simple thoughts and actions. 1. Stop-signal studies of decision and memory. J Exp Psychol Learn Mem Cognit 9:585-606.

Logan GD, Cowan WB (1984) On the ability to inhibit thought and action: a theory of an act of control. Psychol Rev 91:295-327.

Mallet L, Schupbach M, N'Diaye K, Remy P, Bardinet E, Czernecki V, Welter ML, Pelissolo A, Ruberg M, Agid Y, Yelnik J (2007) Stimulation of subterritories of the subthalamic nucleus reveals its role in the integration of the emotional and motor aspects of behavior. Proc Natl Acad Sci USA 104:10661-10666.

Nachev P, Wydell H, O’Neill K, Husain M, Kennard C (2007) The role of the pre-supplementary motor area in the control of action. NeuroImage 36 [Suppl 2]:T155-T163.

Nederkoorn C, Jansen E, Mulkens S, Jansen A (2006) Impulsivity predicts treatment outcome in obese children. Behav Res Ther 45:1071-1075.

Nee DE, Wager TD, Jonides J (2007) Interference resolution: insights from a meta-analysis of neuroimaging tasks. Cogn Affect Behav Neurosci 7:1-17.

Nigg JT (2001) Is ADHD a disinhibitory disorder? Psychol Bull 127:571-598.

Pliszka SR, Liotti M, Woldorff MG (2000) Inhibitory control in children with attention-deficit/hyperactivity disorder: event-related potentials identify the processing component and timing of an impaired rightfrontal response-inhibition mechanism. Biol Psychiatry 48:238-246.

Robinson ES, Eagle DM, Mar AC, Bari A, Banerjee G, Jiang X, Dalley JW, Robbins TW (2007) Similar effects of the selective noradrenaline reuptake inhibitor atomoxetine on three distinct forms of impulsivity in the rat. Neuropsychopharmacology, in press.

Rubia K, Smith AB, Brammer MJ, Taylor E (2003) Right inferior prefrontal 
cortex mediates response inhibition while mesial prefrontal cortex is responsible for error detection. NeuroImage 20:351-358.

Rubia K, Smith AB, Brammer MJ, Toone B, Taylor E (2005) Abnormal brain activation during inhibition and error detection in medicationnaive adolescents with ADHD. Am J Psychiatry 162:1067-1075.

Sakagami M, Tsutsui K, Lauwereyns J, Koizumi M, Kobayashi S, Hikosaka O (2001) A code for behavioral inhibition on the basis of color, but not motion, in ventrolateral prefrontal cortex of macaque monkey. J Neurosci 21:4801-4808.

Schachar RJ, Crosbie J, Barr CL, Ornstein TJ, Kennedy J, Malone M, Roberts W, Ickowicz A, Tannock R, Chen S, Pathare T (2005) Inhibition of motor responses in siblings concordant and discordant for attention deficit hyperactivity disorder. Am J Psychiatry 162:1076-1082.

Schall JD, Stuphorn V, Brown JW (2002) Monitoring and control of action by the frontal lobes. Neuron 36:309-322.
Sowell ER, Thompson PM, Welcome SE, Henkenius AL, Toga AW, Peterson BS (2003) Cortical abnormalities in children and adolescents with attention-deficit hyperactivity disorder. Lancet 362:1699-1707.

Stinear CM, Byblow WD (2003) Role of intracortical inhibition in selective hand muscle activation. J Neurophysiol 89:2014-2020.

Stinear CM, Byblow WD (2004) Impaired modulation of intracortical inhibition in focal hand dystonia. Cereb Cortex 14:555-561.

Stuphorn V, Schall JD (2006) Executive control of countermanding saccades by the supplementary eye field. Nat Neurosci 9:925-931.

Swainson R, Cunnington R, Jackson GM, Rorden C, Peters A, Morris PG, Jackson SR (2003) Cognitive control mechanisms revealed by ERP and fMRI: evidence from repeated task-set switching. J Cogn Neurosci 15:785-799.

Xue G, Poldrack RA, Aron AR (2006) Right inferior frontal cortex is involved in inhibiting both manual and vocal responses. Soc Neurosci Abstr 32:367.5. 